\title{
The meaning and consequences of tuberculosis for an at-risk urban group in Ecuador
}

\author{
Rodrigo X. Armijos, ${ }^{1,2}$ M. Margaret Weigel, ${ }^{2}$ Matilde Qincha, ${ }^{2}$ \\ and Bernarda Ulloa ${ }^{2}$
}

Suggested citation Armijos RX, Weigel MM, Qincha M, Ulloa B. The meaning and consequences of tuberculosis for an atrisk urban group in Ecuador. Rev Panam Salud Publica. 2008;23(3):188-97.

ABSTRACT Objective. To explore knowledge, beliefs, perceptions, and attitudes about tuberculosis (TB) in a high-risk group in Ecuador. This included signs and symptoms, causation, transmission, treatment, treatment adherence, impact on lifestyle and role functioning, and stigma.

Methods. A convenience sample of 212 adults undergoing diagnostic TB testing at a public health facility in Quito, Ecuador, was recruited for the study. Data were collected from subjects during face-to-face interviews using a structured instrument containing closed and openended questions. Descriptive and bivariate statistics were used for quantitative analyses; content analysis was used to analyze qualitative data.

Results. Most subjects were familiar with TB and some of its characteristics and treatment aspects. However, many also held misconceptions or lacked key knowledge which could adversely affect early diagnosis and treatment and adherence to treatment, and thereby allow the disease to spread. Subject education was the single most important predictor of knowledge, beliefs, perceptions, and attitudes followed by gender, age, and prior disease experience. The subjects linked TB to multiple adverse health, economic, psychological, and social consequences, including stigma. Although none knew if they had TB when interviewed, many reported feeling stigmatized just by being tested. The subjects identified a strong need for formal educational opportunities to learn about TB prevention and control but had little access to these.

Conclusions. The study findings highlight a need for enhanced population access to TB education. Health education and social marketing directed toward increasing TB knowledge and changing perceptions and attitudes could ultimately contribute to improved early diagnosis, treatment adherence, prevention, and decreased stigma. This could be accomplished providing that the public health infrastructure is adequate to meet demands.

Key words Tuberculosis, pulmonary, prevention and control; communicable disease; health promotion; Ecuador.

\begin{abstract}
Human Immunology and Nutrition Research Laboratory, Department of Health Promotion, College of Health Sciences, University of Texas at El Paso, El Paso, Texas, U.S.A. (formerly of the Instituto Nacional de Higiene "Leopoldo Izquieta Perez," Ministerio de Salud Pública, Quito, Pichincha, Ecuador.) Send correspondence to R.X. Armijos, Human Immunology and Nutrition Research Laboratory, Department of Health Promotion, College of Health Sciences, University of Texas at El Paso,
\end{abstract}

Tuberculosis (TB) is a major cause of morbidity, mortality, and disability

El Paso, Texas 79912-0581, U.S.A. E-mail: rxarmijos@ utep.edu

2 Department of Microbiology, Instituto Nacional de Higiene "Leopoldo Izquieta Perez," Ministerio de Salud Pública, Quito, Pichincha, Ecuador. worldwide. It is estimated that 8.8 million new cases of TB occur annually causing 1.6 million deaths (1). The disease also accounts for $2.8 \%$ of the total global disability adjusted life year burden (2). The Republic of Ecuador has one of the highest population preva- 
lence (202/100,000 inhabitants) and incidence rates for TB $(131 / 100,000$ inhabitants) and TB mortality (27/ 100,000 inhabitants) estimated for the Americas region (1, 3). Multidrug resistant TB (MDR-TB) also is very common $(1,3)$. Ecuadorian immigrants in the U.S. (4) and Europe $(5,6)$ are at high risk for TB and MDR-TB.

Ecuador has made considerable recent progress in strengthening its national TB control program infrastructure $(7,8)$ including decentralizing treatment facility sites. With the national implementation of Directly Observed Therapy (DOT) strategy, the treatment success rate for new smearpositive TB cases increased from $82 \%$ in 2001 to $85 \%$ in 2005 (1). However, improving disease prevention and early diagnosis is also important especially in high-risk countries such as Ecuador. Efforts in this area could be advanced by a better understanding of the factors that influence healthseeking behavior in the population, especially among high-risk groups.

Studies conducted in diverse global populations have demonstrated the importance of low household income as a major contributor to diagnostic delay of tuberculosis, poor treatment adherence, and treatment failure (9-12). In addition, explanatory models or culturally based explanations of illness and health influence the health-seeking behaviors of persons. These include knowledge, beliefs, and perceptions about the cause of a disease, its signs and symptoms, severity, transmission, options for treatment, and prognosis (13-16).

Individuals also are influenced by what family, friends, and other members of their social network tell them about a disease and its treatment (16, 17), how they personally experience their symptoms, the ability to function, and stigma, as well as their roles within health care systems, their social network and the larger society $(13,14$, 18-21). Understanding these influences can provide important insights into how TB, its diagnosis, treatment, and follow-up are comprehended and experienced. This information can be utilized by TB control programs to shape culturally appropriate messages about illness prevention, diagnosis, and treatment that will make their programs and the services they offer more relevant to the competing needs, demands, and priorities of local populations. However, data on this important topic have not been published for Ecuadorian groups.

The present study was conducted to explore the knowledge, beliefs, and perceptions about TB signs and symptoms, severity, causation, transmissibility, and treatment reported by Ecuadorian subjects. The subjects had been referred for diagnostic TB testing at an urban public health facility because they had symptoms suggestive of TB or because of their status as a household contact of a TB patient. The study also explored reported beliefs, attitudes, and perceptions of the subjects about the impact of $\mathrm{TB}$ on lifestyle, role functioning, and stigma. In addition, perceptions about $\mathrm{TB}$ treatment and barriers to treatment adherence were examined among the subset of subjects with prior disease experience. Finally, it solicited suggestions from the subjects for improving the national TB control program and its services.

\section{METHODS AND MATERIALS}

\section{Study site and subject selection}

Data for the cross-sectional study were collected during a 6-month period (August 1999 to February 2000) at the Instituto Nacional de Higiene "Leopoldo Izquieta Perez" (INHLIP) Tuberculosis Reference Laboratory in Quito, Ecuador. The Ecuadorian Ministry of Public Health (Ministerio de Salud Pública-MSP) has overall responsibility for TB control in Quito. The specific function of the tuberculosis section of the INHLIP microbiology department is diagnosis as TB treatment is carried out at other MSP sites. Health care workers are required to refer individuals who exhibit respiratory symptoms such as persistent cough, hemoptysis, or shortness of breath for more than 15 days to the INHLIP lab for a purified protein derivative (PPD) test and sputum microscopy. Likewise, household contacts are referred for the same procedures.

A convenience sample of 212 adults referred to the INHLIP for suggestive symptoms $(n=129)$ or because of their household contact status $(n=83)$ were recruited for the study. Subjects were enrolled in the study in the consecutive order in which they were referred to the INHLIP. They were included if they were at least 18 years old, did not have any developmental or other conditions that would impede their ability to adequately understand and respond to interview questions, and did not have any other household members participating in the study. None of the prospective subjects recruited for the study declined to participate. The study was approved by the INHLIP administration and research ethics committee of the medical school of the Central University of Ecuador. Subjects went through the informed consent process prior to being enrolled.

The data were collected during faceto-face interviews with subjects using a structured questionnaire. Subjects were first asked to answer a closedended question (yes/no) on a particular topic. This was followed by an open-ended question on the same topic. This strategy allowed the subjects to explain their answers in their own words and permitted further probing by the interviewer. Subject qualitative responses to the openended questions were subsequently grouped into categories for the analyses by the study team anthropologist (M.M. Weigel) to produce general categories or "themes".

The questionnaire collected information on subject sociodemographic and other characteristics. It also collected data on the reported knowledge, beliefs, and perceptions of subjects regarding their familiarity with TB and its symptoms, causes, severity, transmissibility, treatment, and follow-up as well as the impact of TB on lifestyle and role functioning (i.e., a person's ability to perform designated roles at work, home, and in society) and stigma. The open-ended question format also was used to explore sub- 
ject perspectives and priorities for the Ecuadorian national TB control program. In addition, questions were asked of a subset of subjects with prior TB experience regarding their experiences with disease treatment and adherence barriers. The TB status of all subjects was undetermined at the time of the interview. Subjects subsequently diagnosed with TB $(12.7 \% ; 27)$ were referred to a public health facility for treatment as per MSP regulations.

The data were entered into the SPSS database management and statistical analysis system (SPSS, Chicago, Illinois, U.S.A.; version 13.5). Descriptive numerical data are reported as means \pm standard deviations. Categorical data are described as \% (n) or \% ( $n l$ sample size) where only a subset of the study sample was used. Differences between proportions were analyzed using $2 \times 2$ contingency table analysis with Yates corrected $\chi^{2}$ or Fisher exact test, as appropriate. Content analysis was used to analyze the responses to the open-ended qualitative questions.

\section{RESULTS}

\section{Subject characteristics}

Table 1 displays the characteristics of the 212 study participants. Most of the predominantly working class mestizo subjects were female, legally married, and poorly educated. Their ages ranged from 18 to 80 years. Around one-sixth of the subjects reported that they had previously been a TB patient. One-quarter indicated the same for at least one of their immediate family members. Slightly more males $(69.6 \%$; $55)$ than females $(55.6 \% ; 74)$ were referred to the INHLIP because of suggestive TB symptoms, but the difference was not statistically significant $\left(\chi^{2}=3.5 ; P=0.06\right)$.

\section{Disease familiarity and sources of information}

The majority of the subjects $(71.2 \%$; 151) reported that prior to being referred to the INHLIP they were aware

TABLE 1. Sociodemographic and other characteristics of study subjects $(n=212)$ undergoing TB testing in Ecuador, 1999-2000

\begin{tabular}{|c|c|c|}
\hline Subject characteristics & No. & $\%$ \\
\hline \multicolumn{3}{|l|}{ Ethnicity (self-reported) } \\
\hline Mestizo (mixed Spanish-Quechua) & 197 & 92.9 \\
\hline Afro-Ecuadorian & 11 & 5.2 \\
\hline Indigenous & 4 & 1.9 \\
\hline Sex (\% female) & 133 & 62.7 \\
\hline \multicolumn{3}{|l|}{ Age } \\
\hline $18-30$ years & 73 & 34.4 \\
\hline$>30$ years & 139 & 65.6 \\
\hline \multicolumn{3}{|l|}{ Formal education } \\
\hline$\leq 9$ years & 110 & 51.9 \\
\hline$>9$ years & 102 & 48.1 \\
\hline \multicolumn{3}{|l|}{ Marital status } \\
\hline Legally married & 137 & 64.6 \\
\hline Common-law marriage & 9 & 4.2 \\
\hline Single & 51 & 24.1 \\
\hline Separated or divorced & 9 & 4.2 \\
\hline Widowed & 6 & 2.8 \\
\hline \multicolumn{3}{|l|}{ Length of residence in Quito } \\
\hline$<10$ years & 47 & 22.5 \\
\hline $10-19$ years & 34 & 16.3 \\
\hline 20-29 years & 51 & 24.4 \\
\hline$\geq 30$ years & 80 & 36.8 \\
\hline \multicolumn{3}{|l|}{ Home ownership } \\
\hline Own home & 197 & 92.9 \\
\hline Rent home & 11 & 5.2 \\
\hline Other arrangement & 4 & 1.9 \\
\hline \multicolumn{3}{|l|}{ Housing characteristics } \\
\hline Electricity & 206 & 97.2 \\
\hline Municipal sewage hookup & 179 & 84.6 \\
\hline Piped-in water & 189 & 89.2 \\
\hline Municipal garbage pick-up & 191 & 90.1 \\
\hline \multicolumn{3}{|l|}{ Prior disease experience } \\
\hline Prior TB history (self) & 37 & 17.5 \\
\hline Prior TB history (immediate family member) & 56 & 26.4 \\
\hline
\end{tabular}

Note: Some percentage totals may not equal $100 \%$ because of rounding.

of TB, known locally as pulmon picado (ice pick lung) or tisis (consumption). The first term describes the disease as causing bloody holes in the lungs and the second describes its physical effects on the body, i.e., wasting and debilitation. Most of this group (52.3\%; $79 / 151$ ) indicated that their familiarity with TB was based on prior experience either as a former TB patient or as the immediate family member of one. The others reported that they had learned about the illness through casual gossip about others $(28.5 \%$; 43/151), from health education lessons in school $(12.6 \% ; 19 / 151)$, or from popular magazine or newspaper articles that mentioned TB (6.6\%; 10/151). None reported learning about the disease through the public health service or public service announcements. As expected, subjects with a prior personal or family TB history were more likely to report familiarity with TB than others $\left(89.3 \%\right.$ vs. $\left.66 \% ; \chi^{2}=11 ; P=0.001\right)$ as were those who had more than nine years of formal schooling compared to their less well-educated counterparts (78.2\% vs. $\left.61 \% ; \chi^{2}=7.1 ; P=0.008\right)$. In contrast, age, gender, ethnicity, marital status, and other subject characteristics did not predict reported $\mathrm{TB}$ familiarity.

\section{TB signs and symptoms}

The subjects identified an average of $2.9+1.4$ (range 1-6) different signs and symptoms that they reported as 
TABLE 2. Reported knowledge and beliefs (TB characteristics, causation, transmission, treatment, treatment adherence, and follow-up) of study subjects undergoing TB testing in Ecuador, 1999-2000

\begin{tabular}{|c|c|c|}
\hline Responses & No. & $\begin{array}{c}\% \text { of } \\
\text { responses }\end{array}$ \\
\hline \multicolumn{3}{|l|}{ TB severity compared to other illnesses ( $n=169$ responses) } \\
\hline Pneumonia & 69 & 40.8 \\
\hline Cancer & 56 & 33.1 \\
\hline Common cold & 29 & 17.2 \\
\hline Diabetes & 7 & 4.1 \\
\hline HIV/AIDS & 4 & 2.4 \\
\hline Heart attack & 3 & 1.8 \\
\hline \multicolumn{3}{|l|}{ Tuberculosis causation theories ( $n=109$ responses) } \\
\hline Poor nutrition weakens body and allows for TB to develop & 47 & 43.1 \\
\hline Infection (general) or improperly treated common cold or flu infection & 39 & 35.8 \\
\hline Interaction of poor nutrition and infection & 10 & 9.2 \\
\hline Environmental causes & 6 & 5.5 \\
\hline Poor personal hygiene & 4 & 3.7 \\
\hline "Vices" (excessive alcohol, tobacco, sex) & 3 & 2.8 \\
\hline \multicolumn{3}{|l|}{ Primary mode of TB transmission ( $n=184$ responses) } \\
\hline Exposure to coughing, sneezing of infected person (airborne particles) & 82 & 44.6 \\
\hline Contact with fomites (eating utensils, bedding, clothing, towels, etc) & 74 & 40.2 \\
\hline Contact with discarded sputum or urine of infected person & 21 & 11.4 \\
\hline Casual contact with an infected person & 4 & 2.2 \\
\hline Sexual contact with an infected person & 3 & 1.6 \\
\hline \multicolumn{3}{|l|}{ How subject himself/herself may have specifically acquired TB ( $n=64$ responses) } \\
\hline Had contact with infected family member or friend & 34 & 53.1 \\
\hline Had contact with fomites from person with TB & 12 & 19.0 \\
\hline Developed from improperly cured cold & 6 & 9.4 \\
\hline Had lowered defenses due to pregnancy & 6 & 9.4 \\
\hline Had poor nutrition & 2 & 3.1 \\
\hline Was exposed to a sudden change in ambient temperature & 2 & 3.1 \\
\hline Engaged in "vices" such as excessive alcohol, tobacco, and sex & 2 & 3.1 \\
\hline \multicolumn{3}{|l|}{ Major reason why TB needs to be treated ( $n=182$ responses) } \\
\hline To weaken or break illness & 85 & 46.7 \\
\hline To stop disease from worsening & 33 & 18.1 \\
\hline To prevent death or incapacitation & 33 & 18.1 \\
\hline To prevent it from becoming a chronic condition & 17 & 9.3 \\
\hline To prevent it from infecting other persons & 14 & 7.7 \\
\hline \multicolumn{3}{|l|}{ Length of treatment required to cure TB ( $n=125$ responses) } \\
\hline Many months & 76 & 60.0 \\
\hline Many years & 16 & 12.8 \\
\hline Rest of life & 5 & 4.0 \\
\hline Varies according to individual & 28 & 22.4 \\
\hline \multicolumn{3}{|l|}{ Major reason why treatment adherence is important ( $n=203$ responses) } \\
\hline Only way to completely cure TB & 182 & 89.7 \\
\hline Only way to prevent patient from developing drug-resistant TB & 9 & 4.4 \\
\hline To prevent TB from becoming a chronic condition & 7 & 3.4 \\
\hline Because doctors consider it important & 5 & 2.5 \\
\hline \multicolumn{3}{|l|}{ Major reason why treatment follow-up is needed ( $n=197$ responses) } \\
\hline To determine if treatment was successful & 152 & 77.2 \\
\hline To prevent relapse & 44 & 22.3 \\
\hline To see if TB remains under control (incurable disease) & 1 & 0.5 \\
\hline
\end{tabular}

Note: Some percentage totals may not equal $100 \%$ because of rounding.

characteristic of a TB sufferer. These included a chronic or persistent cough (43.4\%; 92), weight loss (38.7\%; 82), malaise $(29.2 \% ; 62)$, increased sputum expectoration $(28.8 \% ; 61)$, anorexia (25.9\%; 55), fatigue $(21.2 \% ; 45)$, bloody, difficult or painful urination $(19.3 \%$;
41), fever $(18.9 \%$; 40), and back pain $(13.7 \%$; 29). Those less frequently identified included breathing difficulty $(10.8 \%$; 23), generalized body pain (9\%; 19), muscle weakness $(7.5 \% ; 16)$, irritability $(7.1 \%$; 15$)$, headache $(6.1 \%$; $13)$, hemoptysis $(5.7 \%$; 12), night sweats $(3.8 \% ; 8)$, pallor $(3.8 \% ; 8)$, dizziness or faintness $(3.3 \% ; 7)$, and chills $(3.3 \% ; 7)$. Few subjects reported that a chronic/persistent or bloody cough by itself was suggestive of TB. Rather, most specified that cough had to be combined with one more symptoms of malnutrition (e.g., weight loss, anorexia) or debilitation (e.g., malaise, fatigue) for it to be suggestive of TB.

\section{Disease severity and causation}

Most subjects $(79.7 \% ; 169)$ indicated that they could rank the severity of TB compared to other illnesses. Although some subjects responded that it is no more serious than a common cold, most ranked TB as serious as potentially fatal illnesses such as pneumonia and cancer (Table 2). Slightly more than half $(51.4 \%$; 109$)$ reported that they knew the cause of TB. Their responses are displayed in Table 2. Most identified poor nutritional status, an infection, or an interaction between the two that causes the body to weaken and become vulnerable to TB. The others attributed it to other causes such as excessive indulgence in certain vices, or exposure to cold. More men than women $\left(35.4 \%\right.$ vs. $14.3 \% ; \chi^{2}=11.7$; $P=0.001)$ and more subjects with more than nine years of education than those with nine or fewer years of education $\left(31 \%\right.$ vs. $\left.8.6 \% ; \chi^{2}=13.1 ; P=0.001\right)$ identified an infectious cause for TB.

\section{Disease transmission}

Eighty-seven percent (184) of the subjects concurred that TB is a transmissible illness. Subjects who had more than nine years of formal education were more likely than their less educated counterparts to report that the disease is transmissible $(92.9 \%$ vs. $\left.77.8 \% ; \chi^{2}=7.8 ; P=0.005\right)$. Of those individuals who reported that $\mathrm{TB}$ is transmissible, $88.6 \%(163 / 184)$ indicated that they could describe how this occurs. The transmission modes most frequently identified were direct exposure to the coughing or sneezing of a person with $\mathrm{TB}$, contact with their 
discarded sputum or urine, or contact with fomites through sharing eating and drinking utensils, towels, blankets, bedding, and clothing (Table 2). Subjects with $\leq 9$ years of education were more likely than others to suggest that transmission of $\mathrm{TB}$ occurs via fomites $\left(53.2 \%\right.$ vs. $24.1 \% ; \chi^{2}=14.8$; $P<0.0001)$ as were those aged $>30$ years compared to their younger counterparts $\left(41.5 \%\right.$ vs. $20.4 \% ; \chi^{2}=7.3$; $P=0.007)$. In contrast, men were less likely than women to indicate that TB can be transmitted by fomites $(41.7 \%$ vs. $\left.23.4 \% ; \chi^{2}=5.9 ; P=0.02\right)$. When subjects were asked to speculate about how they themselves might have possibly developed TB, only $30.2 \%$ (64) could do so. Most of these explained that this could have occurred through close physical contact with an infected person or their fomites (Table 2).

\section{TB treatment, treatment adherence, and follow-up}

The large majority of study subjects (96.7\%; 205) agreed that persons definitively diagnosed with TB require treatment by conventional medicine. When asked to further explain why, most $(88.8 \%$; 182/205) said that they could do so. As Table 2 notes, the most frequent reasons given were that this type of "strong" treatment is the only way to weaken or "break" TB, to keep it from progressing to incapacitation and death. However, only one-quarter of the subjects $(24.9 \%$; $51 / 205)$ who specified the need for conventional medical treatment correctly identified antibiotics as the drugs used to treat TB patients. Table 2 indicates that when subjects were questioned on how long conventional treatment takes to complete, $60 \%$ of those who said that they knew correctly reported treatment requires several months. The others reported it varies according to the individual, lasts for many years, or lasts the rest of a person's life. Most (99\%; 203/205) also agreed that strict treatment adherence is necessary. They explained that this is the only way to ensure that the disease is completely cured (Table 2). Most (96.1\%;
$197 / 205)$ also agreed that a period of post-treatment follow-up is required to assure that a patient is cured and/or to guard against relapse.

\section{Treatment experience}

The subset of 49 subjects who reported prior TB experience were questioned about their own treatment experience or that of their immediate family member. They described a number of major costs for TB treatment including excessive time required for health-seeking (73.5\%; $36 / 49)$, high monetary outlay for treatment $(71.4 \% ; 35 / 49)$, and long travel distances to treatment facilities $(20.4 \%$; $10 / 49)$. They identified several sources of drugs used for treatment. Some obtained them by paying for them at a private pharmacy $(22.4 \% ; 11 / 49)$, others got them free at a MSP facility $(34.7 \% ; 17 / 49)$ but most had used both sources $(57.1 \% ; 28)$. Almost four in ten subjects $(36.7 \% ; 18 / 49)$ admitted that either they or their family member had stopped taking their TB medications for one or more weeks without physician consent. The reasons they cited included a lack of money to buy the TB medications $(38.9 \% ; 7 / 18)$, the patient felt cured $(33.3 \% ; 6 / 18)$, intolerable drug side effects $(22.2 \% ; 4 / 18)$, a drug shortage at the treatment facility $(5.6 \% ; 1 / 18)$, or inability to get permission to leave work to pick up the medications $(5.6 \% ; 1 / 18)$.

\section{Lifestyle and role functioning}

There was general agreement among subjects $(88.2 \%$; 187$)$ that the lifestyle of TB sufferers undergoes significant changes with respect to physical activity, diet, and social interactions. They reported that such changes are needed in order for the person to get better or cured $(54.5 \% ; 102 / 187)$, to reduce the chance of infecting others $(35.3 \%$; $66 / 187)$, or for both reasons $(10.2 \%$; 19/187).

When questioned about the potential impact of the illness on role functioning, around one-half of the sub- jects reported that it significantly affects a person's ability to adequately carry out their duties at their place of employment, home, or school. Of these, 59\% (125) reported that TB has a significant adverse impact on a person's paid employment. Some reasoned that this occurs because TBassociated fatigue and malaise reduces an individual's ability to perform work (59.2\%; 74/125). Others (35.2\%; $44 / 125)$ explained that the constant need for rest or to seek treatment reduces the number of hours that a person can work in paid employment. Some $(5.6 \% ; 7 / 125)$ noted that TB's actual adverse impact is dependent upon disease severity.

Similar to what they reported for paid employment, approximately half of the subjects asserted that TB reduces the ability of individuals to perform housework $(51.9 \%$; 110) or schoolwork (46.7\%; 99). They reasoned that TB-associated fatigue and malaise reduces the ability of patients to perform housework duties $(58.2 \%$; 64/ $110)$ or schoolwork (56.6\%; 56/99). Others indicated that the frequent need of TB sufferers to rest and seek treatment reduced the number of hours they were able to carry out housework $(35.4 \% ; 39 / 110)$ or attend school $(35.6 \% ; 35 / 99)$. The remainder reported that the magnitude of effect on housework $(6.4 \% ; 7 / 110)$ or schoolwork $(7.9 \% ; 8 / 99)$ is individual and depends upon disease severity. Subjects with less formal education $(\leq 9$ years) were more likely than their better educated counterparts to suggest that TB adversely affects a person's ability to perform paid employment (86.9\% vs. $\left.71 \% ; \chi^{2}=5.4 ; P=0.020\right)$ or housework $\left(84.3 \%\right.$ vs. $66.7 \% ; \chi^{2}=5.3$; $P=0.022)$. In contrast, age, gender, marital status, and the other subject characteristics measured in the study did not predict subject response.

\section{Stigma}

Internalized stigma. Seventy-eight percent of the study subjects (166) indicated that they had suffered significant psychological and emotional dis- 
tress after learning that they had to be tested for possible TB. The specific types of distress reported were feelings of isolation and loneliness (44\%; $73 / 166)$, sadness $(42.8 \% ; 71 / 166)$, and shame about possibly having TB (7.2\%; 10/166). Some also mentioned feeling ashamed of having a chronic/ persistent cough $(1.2 \% ; 2 / 166)$ or worry that others would believe they were using their symptoms as an excuse to get out of doing their fair share of work $(6 \% ; 10 / 166)$.
Social stigma. The subjects were questioned about whether or not they had perceived any significant changes in the behavior of their spouse/partner, children, parents, family, friends, or co-workers toward them since learning that they were required to undergo testing for possible TB. As Table 3 notes, a sizeable proportion of subjects responded that they were unsure whether or not the behavior of their social network members had changed or that the question was not applicable to them since they had not yet informed these persons about their situation. The latter was particularly true for non-kin, most of whom were rarely informed. Table 3 also indicates that of those subjects who responded, the most frequent answer given was that they had not perceived any noticeable changes in behavior. They surmised that this was because it had not yet been determined whether or not they actually had TB or that these persons did not fear catching the disease be-

Table 3. Reported perceptions (changes in the behavior of different social network members upon learning subject was undergoing testing for possible TB) of study subjects undergoing TB testing in Ecuador, 1999-2000

\begin{tabular}{|c|c|c|}
\hline Subject responses & No. & $\%$ \\
\hline \multicolumn{3}{|l|}{ Spouse/Partner } \\
\hline \multicolumn{3}{|c|}{ Perceived behavior of spouse/partner after learning subject was being tested for TB ( $n=212)$} \\
\hline Question not applicable/not sure ${ }^{\mathrm{a}}$ & 118 & 55.7 \\
\hline Responded to question & 94 & 44.3 \\
\hline \multicolumn{3}{|l|}{ Reported response } \\
\hline Perceived no noticeable change in behavior toward subject & 59 & 62.8 \\
\hline Perceived positive change: acted supportive & 30 & 31.9 \\
\hline Perceived negative change: acted angry or rejected them & 5 & 5.3 \\
\hline \multicolumn{3}{|c|}{ Children } \\
\hline \multicolumn{3}{|c|}{ Perceived behavior of children after learning subject was being tested for TB $(n=212)$} \\
\hline Question not applicable/not sure ${ }^{a}$ & 120 & 56.6 \\
\hline Responded to question & 92 & 43.4 \\
\hline \multicolumn{3}{|l|}{ Reported response } \\
\hline Perceived no noticeable change in behavior toward subject & 58 & 63.0 \\
\hline Perceived positive change: acted supportive & 30 & 32.6 \\
\hline Perceived negative change: acted angry or rejected them & 4 & 4.3 \\
\hline \multicolumn{3}{|l|}{ Parents } \\
\hline \multicolumn{3}{|c|}{ Perceived behavior of parents after learning subject was being tested for TB $(n=212)$} \\
\hline Question not applicable/ not sure ${ }^{a}$ & 154 & 72.6 \\
\hline Responded to question & 58 & 27.4 \\
\hline \multicolumn{3}{|l|}{ Reported response } \\
\hline Perceived no noticeable change in behavior toward subject & 36 & 62.1 \\
\hline Perceived positive change: acted supportive & 19 & 32.8 \\
\hline Perceived negative change: acted angry or rejected them & 3 & 5.2 \\
\hline \multicolumn{3}{|c|}{ Friends } \\
\hline \multicolumn{3}{|c|}{ Perceived behavior of friends after learning subject was being tested for TB $(n=212)$} \\
\hline Question not applicable/not sure ${ }^{a}$ & 202 & 95.3 \\
\hline Responded to question & 10 & 4.7 \\
\hline \multicolumn{3}{|l|}{ Reported response } \\
\hline Perceived no noticeable change in behavior toward subject & 8 & 80.0 \\
\hline Perceived positive change: acted supportive & 0 & 0.0 \\
\hline Perceived negative change: acted angry or rejected them & 2 & 20.0 \\
\hline \multicolumn{3}{|c|}{ Co-Workers } \\
\hline \multicolumn{3}{|c|}{ Perceived behavior of co-workers after learning subject was being tested for TB $(n=212)$} \\
\hline Question not applicable/not sure ${ }^{a}$ & 205 & 96.7 \\
\hline Responded to question & 7 & 3.3 \\
\hline \multicolumn{3}{|l|}{ Reported response } \\
\hline Perceived no noticeable change in behavior toward subject & 5 & 71.4 \\
\hline Perceived positive change: acted supportive & 0 & 0.0 \\
\hline Perceived negative change: acted angry or rejected them & 2 & 28.6 \\
\hline
\end{tabular}

Note: Some percentage totals may not equal $100 \%$ because of rounding.

a Subjects reported that the question is not applicable to their situation since (a) they had not yet informed the person(s) in question that they had to undergo testing for possible TB; $(b)$ they did not have said relationship (e.g., no spouse, children, or co-workers); or (c) were unsure. 
cause it is treatable. Furthermore, of the subjects who perceived a change in the behavior of their spouse/partner, children, and parents, most indicated that these had been more supportive toward them, displaying worry or concern or performing acts of kindness, different from what they noted for non-kin (i.e., friends, co-workers).

Subjects also were questioned as to whether the behavior of their employer seemed to have changed toward them since finding out they might have TB. Half of the 49 subjects who said that they had a current/recent employer reported that they had never told them because they were afraid that they would be terminated. Of those who informed their employer, most said their employer had not changed their behavior toward them or had acted supportive. In contrast, several mentioned that their most recent employer had immediately fired them after finding out they were undergoing TB testing.

Stigma attitudes. Attitudes on social stigma related to TB were explored by posing two open-ended hypothetical scenarios to the subjects. In the first, the subjects were asked what they would do if they were the owner of a business and discovered that one of their employees had TB. Ten of the 212 subjects reported that they did not know or were unsure about what action they might take. Of those who were able to offer a response, $63.4 \%$ $(126 / 202)$ indicated that they would permit the person to remain in their employment and help them to get treatment. One-sixth $(16.8 \%$; 34/202) indicated that they would allow the worker to remain in their employment but would isolate him/her from their customers and other employees. In contrast, $15.8 \%(32 / 202)$ noted they would immediately terminate the employee. Five percent (10/202) also said that they would fire them but help them find treatment.

Subjects over 30 years old were more likely than younger subjects $\left(25.8 \%\right.$ vs. $\left.8 \% ; \chi^{2}=9.7 ; P=0.002\right)$ to report that they would terminate any employee diagnosed with TB. This was also the case for subjects with less than 9 years of formal education compared to their more well educated counterparts $\left(32.9 \%\right.$ vs. $6.5 \% ; \chi^{2}=9.1$; $P=0.001)$. More women than men indicated that they would keep their employee and help them to get treatment ( $28.9 \%$ vs. $5.4 \% ; \chi^{2}=8.7 ; P=0.003$ ).

In the second hypothetical situation, subjects were asked what they would do if a person with TB applied for work as a domestic employee inside their home. Twelve of the 212 study subjects $(5.7 \%)$ reported that they were unsure what they would do in such a situation. Seventy-eight percent (156/ 200) of those who said that they knew what they do indicated that they would refuse to hire them, compared to $22 \%(44 / 212)$ who indicated that the person's TB status was not a problem. The specific reasons given by the subjects who said that they would refuse to hire a domestic worker were that they would be fearful the person would pass TB to them or their family $(152 / 156 ; 97.4 \%)$ or because TB's debilitating effects would make the prospective employee unfit for work $(2.6 \% ; 4 / 156)$. The explanations given by the subjects who said that they would consider hiring such an employee were that if the person was being treated, they would not be able to pass on the disease $(50 \% ; 22 / 44)$, that the person would not be able to spread the disease if proper precautions are taken (i.e., fomite control) $(34.1 \% ; 15 / 44)$, or that it is the humanitarian thing to do $(15.9 \% ; 7 / 44)$. Younger subjects ( $\leq 30$ years) were more likely than those who were older (> 30 years) to report that they would consider hiring a person with $\mathrm{TB}$ to work inside their home $(31.8 \%$ vs. $\left.17.3 \% ; \chi^{2}=5.5 ; P=0.03\right)$. Education, prior disease experience, marital status, and other subject characteristics did not predict their response.

\section{National TB program improvement}

The subjects were asked to make suggestions for improving the national TB control program for the purpose of gaining insight into their perspectives and priorities. Three major themes were identified from their responses. The most frequently mentioned (63.2\%; 134) was the provision of temporary economic assistance for TB patients and their households. The subjects explained that patients are at risk for severe financial hardships caused by job loss, inability to work full-time because of debilitating symptoms, and the high cost of seeking treatment. The second theme $(57.5 \%$; 122) identified improving support services for TB patients and their families. Specific suggestions included: providing counseling/other psychosocial support services for patients and family members; providing individualized TB education to patients and families, emphasizing the importance of treatment adherence and infection control; improving access to diagnostic and treatment service; and monitoring TB patients to ensure treatment adherence and follow-up. The third major theme $(50.5 \% ; 107)$ focused on increasing population-wide TB education/health promotion efforts by national public health authorities. Their specific suggestions were to increase national BCG vaccination efforts and to launch a national TB education campaign carried out through public media channels and in schools, universities, churches, neighborhood groups, jails, and places of employment.

\section{DISCUSSION}

Most of the high-risk subjects were familiar with TB and recognized many of its characteristic signs and symptoms, its serious nature, and the importance of conventional medical treatment. However, most did not know that TB is treated with antibiotic drugs, did not know its cause, and did not know how they might have contracted it. However, many subjects appeared to recognize the importance of treatment adherence, a cornerstone of effective disease control $(13,17)$. Most recognized that the illness is contagious but disagreed on how it is transmitted, i.e., from contaminated air, bodily secretions, or fomites. The belief that fomites are responsible for 
TB transmission is common throughout Latin America and other regions $(14,17,22-26)$. This belief is more common among people with less education $(17,25)$ and women $(23)$.

Prior studies have not examined the models that Ecuadorian groups use to explain TB. Explanatory models previously described for other illnesses indicate that they often include elements of germ theory, 16th century humoral medicine variants, locally evolved or personal beliefs, and in some cases, divine intervention (27-29). The explanations for TB offered by subjects in our study included a belief that TB germs are present in airborne/other bodily secretions, contaminated fomites, or arise from living in dirty or unsanitary conditions. The notion that illnesses arise from humoral or other imbalances in the body is reported to be common throughout many areas of the world, including the Americas. Similar to what our Ecuadorian study subjects reported for $\mathrm{TB}$, these include sudden or prolonged exposure to cold ambient temperatures $(14,26)$ especially in a person with a pre-existing respiratory illness $(14,26)$, excessive indulgence in vices considered to make the body "hot" $(13,14,17)$, and disturbances in dietary/nutritional balance $(14,17,26)$.

The study results underscore the substantial health, economic, psychological, and social consequences imposed not only upon the TB sufferer but also their families. The physical effects of the disease itself and the large amount of time and cash required for seeking treatment seriously impair the ability of TB patients to function in paid employment and at home and in school. Another concern is loss of paid employment due to stigma and the fear of contagion by employers. These have implications for TB control since significant delays in TB diagnosis and poor treatment adherence have been linked with out-of-pocket expenses associated with seeking treatment and income reductions in poor households $(11,30)$. Low-income patients, who constitute the majority of TB patients in Ecuador, could greatly benefit from financial assistance in the form of cash payments, food, medicine, and other out-ofpocket expenses related to treatment. Prior studies have demonstrated that such incentives can significantly improve early diagnosis and treatment adherence even in poorly educated, low-income patients $(12,17)$.

The study results support the notion that TB is a highly stigmatized disease in Ecuadorian society. Although subjects did not yet know whether or not they had TB at the time they were interviewed, many of them reported that just the possibility caused them to feel depressed, lonely, isolated, and/or ashamed, similar to the type of internalized stigma that persons with confirmed diagnosis often experience (13, $18,19,31)$. This occurred irrespective of subject education, gender, age, or TB experience. The study findings also are consistent with the notion that social stigmatization is inversely associated with the degree of kinship (32). Few subjects indicated perceiving any differences in the behavior of close kin and if they did, they appeared more supportive, like that noted for other groups $(13,17,20)$. This is important since social support provided by family often plays a pivotal role in promoting early TB diagnosis and adherence to treatment $(32,33)$.

The strong social stigma associated with TB appeared to be the major reason why so few subjects disclosed their status to anyone but their closest family members, similar to what has been noted for patients with a positive diagnosis (20). This also is important since the fear of social isolation and segregation can result in treatment delay and reduce the treatment adherence $(13,14)$. As suggested by the subjects themselves, providing counseling and other psychosocial support could help patients and their families to better cope with TB stigma. This assistance could be provided by the social workers and psychologists already in place in the public health care system.

It was surprising to find that none of the subjects identified the Ecuadorian public health service or mass media public service announcements as the source of their TB information and only a few identified school health lessons or mention of the disease in the popular press. Instead, most subjects had learned about TB only after they or a close family member contracted the disease, or from hearing gossip. This finding, along with the suggestions offered by the subjects, indicate that opportunities are being missed by the Ecuadorian public health service and health care providers for educating the population. One way that this could be addressed is by including TB education during routine health visits or in the course of the periodic mass immunization or de-worming campaigns carried out by the MSP. Another could be through collaboration among Ministries of Public Health, Education, Social Welfare, and Government, NGOs, and other local institutions. These could work together to provide TB education/health promotion through public and private schools, neighborhood associations, churches, day care centers, employment sites, jails, and community health fairs. Some of this information could be provided by trained lay health educators/promoters.

One of the most important strategies for achieving widespread dissemination and changing behavior is through the coordinated use of mass media. Ecuador has a history of effective national social marketing campaigns that focus on prevention of HIV/AIDS, iodine deficiency disorder, and promotion of childhood immunization, breastfeeding, and family planning, among others (34-36). The use of proven, accepted spokespersons, such as the Maximo toucan character (37), could be used to inform about TB and the importance of early diagnosis, treatment, and treatment adherence as well as to reduce stigma by addressing common concerns such as those voiced by subjects in this study. However, it is important to caution that the increased demand for TB diagnosis and treatment resulting from successful health education and social marketing will have little or no effect in reducing the population burden unless these services are accessible to patients.

The comments from the subset of patients with prior TB experience pinpoint 
some of the areas where investment is needed. These include the decentralization of services, making them more convenient for patients; ensuring a consistent and free supply of all of the prescribed antibiotic drugs; reducing the time between diagnosis and treatment initiation; and better patient education about treatment adherence.

The potential limitations of this exploratory study should be taken into account when interpreting its results. One of these was the use of a nonrandom sampling method which could have introduced bias into the results. Convenience sampling requires caution when generalizing the study findings to other groups. Individual experiences may vary for lower or higher risk groups, for rural inhabitants, and for persons with different age, education, income, disease experience, health care access, or other characteristics. Another possible limi- tation was the relatively small sample size that could have introduced sampling error. Future studies are required to replicate the study findings. These should be conducted at other urban sites and employ larger sample sizes.

\section{Conclusion}

In conclusion, tuberculosis continues to be a highly stigmatized disease in Ecuadorian society. Many individuals fear catching it and want more formal educational opportunities to learn about its prevention and control. However, they have very few opportunities to do so. Improvement can be made by increasing exposure to $\mathrm{TB}$ education/health promotion messages delivered using a variety of different methods and mediums. The study identified pre-existing sub- ject knowledge, beliefs, perceptions, and attitudes that can be reinforced (e.g., treatment adherence is important) or corrected (e.g., TB is not spread by fomites) by health education/ promotion and social marketing interventions. In addition to children, the messages should be tailored to target more poorly educated adults in the population as they are more likely to have the most TB misconceptions, including fear about TB, but also because they tend to be low income persons at higher risk for the disease.

Acknowledgments. This study was supported in part by funding from the Fundación "Biociencias," Quito, Ecuador. The authors also gratefully acknowledge the technical assistance of Guadalupe Perez de Sierra, Director of the Instituto Nacional de Higiene, Quito.

\section{REFERENCES}

1. World Health Organization (WHO). Global tuberculosis control surveillance, planning, financing. WHO report 2007. (WHO/HTM/ TB/2007.376). Geneva: WHO; 2007. Available from: http://www.who.int/tb/publications/ global_report/2007/download_centre/en/ index.html. Accessed 15 November 2007.

2. World Health Organization (WHO). Special Programme for Research and Training in Tropical Diseases (TDR) [Internet site]. Tuberculosis. Available from: http://www.who. $\mathrm{int} / \mathrm{tdr} /$ diseases/tb/default.htm. Accessed 20 December 2006.

3. Pan American Health Organization (PAHO). Epidemiological status of TB (Region of the Americas, 2004) [Internet site]. Available from: http://www.paho.org/english/ad/ $\mathrm{dpc} / \mathrm{cd} / \mathrm{tb}$-2004-sit-epi.ppt. Accessed $20 \mathrm{De}-$ cember 2006.

4. United States Department of Health and Human Services, Centers for Disease Control and Prevention, Division of Tuberculosis Elimination, National Center for HIV, STD and TB Prevention. Trends in tuberculosis-United States, 2004. MMWR. 2005;54(10): 245-9.

5. Codecasa LR, Porretta AD, Gori A, Franzetti F, Degli Esposti A, Lizioli A, et al. Tuberculosis among immigrants from developing countries in the province of Milan, 1993-1996. Int J Tuberc Lung Dis. 1999;3(7):589-95.

6. Iñigo J, Arce A, Rodríguez E, García de Viedma D, Palenque E, Ruiz Serrano MJ, et al. Tuberculosis trends in Madrid, 1994-2003: impact of immigration and HIV infection. Int J Tuberc Lung Dis. 2006; 10(5):550-3.
7. Oxlade O, Vaca J, Romero E, Graham B, Hernandez $\mathrm{L}$, Tannenbaum $\mathrm{T}$, et al. The longterm health and economic benefits of DOTS implementation in Ecuador. Can J Public Health. 2006;97(1):14-9.

8. Vaca J, Peralta H, Gresely L, Cordova R, Kuffo $\mathrm{D}$, Romero $\mathrm{E}$, et al. DOTS implementation in a middle-income country: development and evaluation of a novel approach. Int J Tuberc Lung Dis. 2005;9(5):521-7.

9. Jackson S, Sleigh AC, Wang GJ, Liu XL. Poverty and the economic effects of TB in rural China. Int J Tuberc Lung Dis. 2006; 10(10):1104-10.

10. Cambanis A, Yassin MA, Ramsay A, Bertel Squire S, Arbide I, Cuevas LE. Rural poverty and delayed presentation to tuberculosis services in Ethiopia. Trop Med Int Health. 2005; 10(4):330-5.

11. Needham DM, Godfrey-Faussett P, Foster SD. Barriers to tuberculosis control in urban Zambia: the economic impact and burden on patients prior to diagnosis. Int J Tuberc Lung Dis. 1998;2(10):811-7.

12. Farmer $\mathrm{P}$, Robin $\mathrm{S}$, Ramilus $\mathrm{SL}$, Kim JY. Tuberculosis, poverty, and "compliance": lessons from rural Haiti. Semin Respir Infect. 1991;6(4):254-60.

13. Liefooghe R, Baliddawa JB, Kipruto EM, Vermeire C, De Munynck AO. From their own perspective: a Kenyan community's perception of tuberculosis. Trop Med Int Health. 1997;2(8):809-21.

14. Jaramillo E. Pulmonary tuberculosis and health-seeking behaviour: how to get a de- layed diagnosis in Cali, Colombia. Trop Med Int Health. 1998;3(2):138-44.

15. Coreil J, Lazardo M, Heurtelou M. Cultural feasibility assessment of tuberculosis prevention among persons of Haitian origin in South Florida. J Immig Health. 2004;6(2):63-69.

16. Rubel AL, Garo LC. Social and cultural factors in the successful control of tuberculosis. Public Health Rep. 1992;107(6):626-36.

17. Baldwin MR, Yori PP, Ford C, Moore DA, Gilman RH, Vidal C, et al. Tuberculosis and nutrition: disease perceptions and health seeking behavior of household contacts in the Peruvian Amazon. Int J Tuberc Lung Dis. 2004;8(12):1484-91.

18. Kelly P. Isolation and stigma: the experience of patients with active tuberculosis. J Community Health Nurs 1999;16(4):233-41.

19. Macq J, Solis A, Martinez G. Assessing the stigma of tuberculosis. Psychol Health Med. 2006;11(3):346-52.

20. Macq J, Solis A, Martinez G, Martiny P, Dujardin $\mathrm{B}$. An exploration of the social stigma of tuberculosis in five "municipios" of Nicaragua to reflect on local interventions. Health Policy. 2005;74(2):205-17.

21. Marra CA, Marra F, Cox VC, Palepu A, Fitzgerald JM. Factors influencing quality of life in patients with active tuberculosis. Health Qual Life Outcomes. 2004;2:58-68.

22. Poss J. The meanings of tuberculosis for Mexican migrant farmworkers in the United States. Soc Sci Med. 1998;47(2):195-202.

23. Hoa NP, Thorson AE, Long NH, Diwan VK. Knowledge of tuberculosis and associated 
health-seeking behaviour among rural Vietnamese adults with a cough for at least three weeks. Scand J Public Health Suppl. 2003;62: 59-65.

24. Long NH, Johansson E, Diwan VK, Winkvist A. Fear and social isolation as consequences of tuberculosis in Viet Nam: a gender analysis. Health Policy. 2001;58(1):69-81.

25. Portero NJ, Rubio YM, Pasicatan MA. Socioeconomic determinants of knowledge and attitudes about tuberculosis among the general population at Metro Manila, Philippines. Int J Tuberc Lung Dis. 2002; 6(4):301-6.

26. Alvarez-Gordillo GC, Alvarez-Gordillo JF, Dorantes-Jiménez JE, Halperin-Frisch D. Percepciones y prácticas relacionadas con la tuberculosis y la adherencia al tratamiento en Chiapas, México. Salud Pública Méx. 2000; 42(6):520-8.

27. Weigel MM, Armijos RX. The traditional and conventional medical treatment of cutaneous leishmaniasis in rural Ecuador. Rev Panam Salud Publica. 2001;10(6): 395-403.
28. Ortega F. Systemes de sante et medecine traditionnelle en Equateur. Dev Sante. 1988;(78): 25-7.

29. Pedersen D, Coloma C. Traditional medicine in Ecuador: the structure of the non-formal health systems. Soc Sci Med. 1983;17(17):1249-55.

30. Kamolratanakul P, Sawert H, Kongsin $S$, Lertmaharit S, Sriwongsa J, Na-Songkhla S, et al. Economic impact of tuberculosis at the household level. Int J Tuberc Lung Dis. 1999; 3(7):596-602.

31. Jaramillo E. Tuberculosis and stigma: predictors of prejudice against people with tuberculosis. J Health Psych. 1999;4(1):71-9.

32. Liefooghe R, Michiels N, Habib S, Moran MB, De Muynck A. Perception and social consequences of tuberculosis: a focus group of tuberculosis patients in Sialkot, Pakistan. Soc Sci Med. 1995;41(12):1685-92.

33. Eastwood SV, Hill PC. A gender-focused qualitative study of barriers to accessing tuberculosis treatment in the Gambia, West Africa. Int J Tuberc Lung Dis. 2004;8(1):70-5.
34. Hornick R (ed). Public health communication. Evidence for behavior change. Mahwah, NJ: Lawrence Erlbaum Associates; 2002.

35. Favin M, Griffiths M. Social marketing of micronutrients in developing countries [published for the Population and Human Resources Department, The World Bank]. Washington, D.C.: Manoff Group; 1992. Available at: http:// www.manoffgroup.com/resources/socmark micro.pdf. Accessed 15 November 2007.

36. The United Nations Children's Fund (UNICEF). Ecuador; Activities; Health and Nutrition [Internet site]. Available from http://www. unicef.org/ecuador/health_nutrition.html. Accessed 16 November 2007.

37. The United Nations Children's Fund (UNICEF) Maximo [Internet site]. Available at: http:// www.awn.com/unicef/maximo.html. Accessed 16 November 2007.

Manuscript received 5 January 2007. Revised version accepted for publication 3 January 2008.

RESUMEN Objetivo. Explorar los conocimientos, las creencias, las percepciones y las actitudes sobre la tuberculosis (TB) en un grupo de alto riesgo en Ecuador. Se abarcaron los signos y síntomas, la causalidad, la transmisión, el tratamiento, la adhesión al tratamiento, el impacto en el estilo de vida y el desempeño de funciones, y el estigma.

\section{Significado y consecuencias de la tuberculosis para un grupo urbano de riesgo en Ecuador}

Palabras clave
Métodos. Para el estudio se seleccionó una muestra de conveniencia de 212 adultos en proceso de diagnóstico de TB en una institución pública de salud de Quito, Ecuador. Los datos de los participantes se obtuvieron en entrevistas presenciales mediante una encuesta estructurada que contenía preguntas cerradas y abiertas. Se aplicó el análisis de contenido para procesar los datos cualitativos y se emplearon pruebas estadísticas descriptivas y bifactoriales para el análisis cuantitativo.

Resultados. La mayoría de los participantes estaban familiarizados con la TB, algunas de sus características y aspectos de su tratamiento. Sin embargo, muchos mantenían errores conceptuales o carecían de conocimientos clave que podrían influir negativamente sobre el diagnóstico temprano, el tratamiento y la adhesión al tratamiento, y por ende facilitaría la diseminación de la enfermedad. El nivel educacional de la persona fue el principal factor individual de predicción de los conocimientos, las creencias, las percepciones y las actitudes, seguido del sexo, la edad y las experiencias previas con la enfermedad. Las personas vinculaban la TB con numerosas consecuencias adversas, tanto para la salud y la economía personal, como psicológicas y sociales, incluida la estigmatización. A pesar de que al ser entrevistados ninguno sabía si tenía TB, muchos dijeron sentirse estigmatizados solo por someterse a la prueba. Los participantes reconocieron una gran necesidad de oportunidades educativas formales para aprender sobre la prevención y el control de la TB, pero tendrían poco acceso a ellas.

Conclusiones. Estos resultados destacan la necesidad de aumentar el acceso de la población a la educación sobre TB. La educación sanitaria y la mercadotecnia social dirigidas a aumentar los conocimientos sobre la TB y a cambiar las percepciones y actitudes podrían contribuir a mejorar el diagnóstico, la adhesión al tratamiento, la prevención y la disminución del estigma. Esto se podría lograr si la infraestructura de salud pública se adecuara a estas necesidades.

Tuberculosis pulmonar, prevención y control; enfermedades transmisibles; promoción de la salud; Ecuador. 